\title{
Sleep apnoea in heart failure
}

\author{
R. Schulz*, A. Blau\#, J. Börgelø, H.W. Duchna ${ }^{+}$, I. Fietze ${ }^{\#}$, I. Koper ${ }^{\S}$, R. Prenzel ${ }^{f}$, \\ S. Schädlich**, J. Schmitt ${ }^{\# \#}$, S. Tasci ${ }^{\star \uparrow}$ and S. Andreas ${ }^{++}$for the working group \\ "Kreislauf und Schlaf" of the German Sleep Society (DGSM)
}

ABSTRACT: Studies from the USA have reported that sleep apnoea is common in congestive heart failure (CHF), with Cheyne-Stokes respiration (CSR) being the most frequent type of sleepdisordered breathing (SDB) in these patients. Within the present study, the authors sought to assess the prevalence and type of SDB among CHF patients in Germany.

A total of 203 CHF patients participated in this prospective multicentre study. All patients were stable in New York Heart Association classes II and III and had a left ventricular ejection fraction (LVEF) $<\mathbf{4 0 \%}$. The patients were investigated by polygraphy and all data were centrally analysed. Patient enrolment was irrespective of sleep-related symptoms.

The majority of patients were male with a mean age of 65 yrs and hospitalised. Of the 203 patients, $145(71 \%)$ had an apnoea/hypopnoea index $>10 \cdot h^{-1}$, obstructive sleep apnoea (OSA) occurred in $43 \%(n=88)$ and CSR in $28 \%(n=57)$ of patients.

The prevalence of sleep-disordered breathing is high in patients with stable severe congestive heart failure from a European population. As sleep-disordered breathing may have a negative impact on the prognosis of congestive heart failure, a sleep study should be performed in every patient with congestive heart failure and a left ventricular ejection fraction of $<40 \%$. This diagnostic approach should probably be adopted for all of these patients irrespective of the presence of sleep-related symptoms.

KEYWORDS: Cheyne-Stokes respiration, congestive heart failure, obstructive sleep apnoea

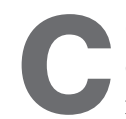

ongestive heart failure (CHF) is a very common disorder carrying a poor prognosis. In Europe, it is estimated that $\sim 14$ million people suffer from CHF with $>3$ million new cases diagnosed each year [1]. The 5-yr mortality rates of CHF range 40-60\% [2].

Sleep-disordered breathing (SDB) has been reported to occur frequently in CHF patients with a left ventricular ejection fraction (LVEF) $<40 \%$. Epidemiological studies performed in the USA in the 1990s described prevalence rates for SDB in these patients of $40-70 \%$ [3-5]. These studies have mainly investigated ambulatory male patients in New York Heart Association (NYHA) classes II and III. Most studies have found Cheyne-Stokes respiration (CSR) as the predominant type of SDB, whereas obstructive sleep apnoea (OSA) was less frequently observed [3-5].

The results of the above cited studies may not be valid for patients outside the USA for various reasons. For example, ethnicity may influence the occurrence of SDB due to differences in respiratory chemosensitivity, craniofacial morphology

For editorial comments see page 1073. and the level of obesity. Furthermore, pharmacotherapy of CHF may differ between countries, which would impact on the frequency and severity of SDB in these patients. To date, however, there is a paucity of large-scale European studies investigating the epidemiology of SDB in CHF. Within the present study the authors sought to address this issue. A prospective multicentre study was performed to determine the prevalence of SDB and its relative distribution (i.e. occurrence of CSR versus OSA) among stable CHF patients in Germany.

\section{PATIENTS AND METHODS}

\section{Patient recruitment}

The patients participating in the present study were prospectively enrolled at nine medical centres located throughout Germany (University of Giessen Lung Centre, Giessen $(n=23)$; Charité University Hospital, Berlin $(\mathrm{n}=12)$; Ruhr University Hospital-Bochum, Bochum $(n=30)$; Sana Hospital $(n=19)$ and Pius Hospital $(n=19)$, Oldenburg; Hospital Martha-Maria, Halle Dolau, $(n=21)$, Theresien Hospital, Mannheim $(n=39)$; University Hospital Bonn, Bonn $(n=10)$; and University Hospital Gottingen, Gottingen $(n=30))$. The main inclusion criterion was the
AFFILIATIONS

*University of Giessen Lung Centre, Giessen,

\#Charité University Hospital Berlin, Sleep Disorders Centre, Department of Cardiology/ Pulmonary Medicine, 'Depts of Cardiology and +Pulmonary Medicine, Ruhr University Hospital-Bochum, Bochum,

§Sana Hospital, Schleswig-Holstein, and

${ }^{f}$ Pius Hospital, Niedersachsen, Oldenburg,

**Department of Internal Medicine II Hospital Martha-Maria Halle-Dolau,

\#\# Department of Internal Medicine III, Theresien Hospital, Mannheim,

- "Department of Cardiology/

Pulmonary Medicine, University Hospital Bonn, Bonn, and +Department of Cardiology/ Pulmonary Medicine, University Hospital Gottingen, Gottingen, Germany.

CORRESPONDENCE

R. Schulz

University of Giessen Lung Center Klinikstr. 36

35392 Giessen

Germany

Fax: 496419947999

E-mail: Richard.Schulz@innere.

med.uni-giessen.de

Received:

March 152006

Accepted after revision:

February 272007

STATEMENT OF INTEREST

Support statements for $\mathrm{S}$. Andreas and for the present study can be found at www.erj.ersjournals.com/ misc/statements.shtml

European Respiratory Journal Print ISSN 0903-1936 Online ISSN 1399-3003 
presence of CHF with a LVEF $<40 \%$ (as determined by transthoracic echocardiography). Furthermore, the patients had to be stable in NYHA classes II or III. Exclusion criteria were the following: age $<18$ yrs or $>80$ yrs, clinical signs of decompensated CHF (oedema etc.), myocardial infarction within the last 6 months, significant chronic obstructive pulmonary disease (i.e. forced expiratory volume in one second (FEV1)/inspiratory vital capacity (IVC) $<65 \%$ of predicted) and known drug addiction. Patient enrolment was independent of the presence of sleep-related symptoms (i.e. snoring, witnessed apnoeas, excessive daytime sleepiness). Patients were allowed to enter the study as either ambulatory or hospitalised. The study was started in April 2004 and completed in January 2005. The study protocol had been approved by the local ethics committees and all patients had given their informed written consent.

\section{Patient assessement}

The anthropometric parameters of the patients were determined, i.e. age, sex and body mass index. The main cause of $\mathrm{CHF}$ was specified, i.e. coronary artery disease, idiopathic dilated cardiomyopathy, arterial hypertension etc. and the NYHA class was determined.

The current use of cardiac-specific medications was evaluated, i.e. angiotensin-converting enzyme (ACE) inhibitors or angiotensin II blockers, $\beta$-blockers, aldosterone antagonists, diuretics and digitalis glycosides. It was noted whether an implantable cardioverter-defibrillator or a biventricular assist device had been inserted. All patients were investigated by transthoracic echocardiography to determine LVEF (normal: 60-70\%). Furthermore, a standard 12-lead ECG was obtained to determine whether the patient was in sinus rhythm or atrial fibrillation. Finally, pulmonary function testing with arterial blood gas analysis was performed. Among others, FEV1, IVC, the ratio of FEV1/IVC as well as oxygen tension and carbon dioxide tension $\left(\mathrm{PCO}_{2}\right.$; in $\left.\mathrm{mmHg}\right)$, were determined.

\section{Polygraphy}

Prior to polygraphy, all patients completed the Epworth Sleepiness Scale (range 0-24) to assess their level of daytime sleepiness. The Stardust II system (Respironics Inc., Herrsching, Germany) was used for polygraphy. This device records oxygen saturation $\left(\mathrm{Sa}_{2} \mathrm{O}_{2}\right)$ and cardiac frequency by fingertip pulse oximetry. Airflow was monitored by a pressure cannula attached to the patient's nostrils, breathing efforts were measured by an inductive plethysmographic belt tightly wrapped around the chest and finally, snoring and body position were registered. All data were stored on CD-ROM for subsequent analysis. This was carried out centrally at the sleep laboratory of the Charité University Hospital (Berlin) with the investigator (A. Blau) blinded to the patients' characteristics.

All apnoeas/hypopnoeas had to last $>10 \mathrm{~s}$ and an apnoea/ hypopnoea index $(\mathrm{AHI})>10 \cdot \mathrm{h}^{-1}$ of time in bed was considered as diagnostic of SDB. In the case of apnoeas, there had to be an absence of airflow.

Obstructive apnoeas were diagnosed if the respiratory efforts continued during the breathing pauses; otherwise these events were classified as central apnoeas. Hypopnoeas were defined by a reduction in respiratory amplitude of $\geqslant 50 \%$ when compared with the preceding signals. Obstructive hypopnoeas had to display persistent and/or increasing effort and snoring during the event, with associated inspiratory flow limitation on the nasal pressure signal. Hypopnoeas were scored as central when there was an absence of these findings. According to the criteria established by JAVAHERI and COworkers [3, 4], OSA was present if the obstructive AHI was $>10 \cdot \mathrm{h}^{-1}$ and the central AHI accounted for $\leqslant 50 \%$ of the total AHI. CSR was diagnosed if the obstructive AHI was $<10 \cdot \mathrm{h}^{-1}$ and the central AHI comprised $>50 \%$ of the total AHI. In addition, CSR was requested to show a typical waxing-andwaning pattern of hyperventilatory phases.

\section{Data analysis}

All data were entered into a web-based questionnaire for statistical analysis. Data are reported as mean \pm SEM unless otherwise indicated. Direct comparisons of data among the groups with OSA, CSR and without SDB (i.e. without OSA and CSR) were performed by analysis of variance with post hoc correction for multiple comparisons by Tukey's test. A p-value $<0.05$ was regarded as statistically significant.

\section{RESULTS}

\section{Patient characteristics}

A total of 203 patients were enrolled in the present study. The characteristics of the study population are summarised in table 1 . The majority of patients were male with a mean age of 65 yrs and hospitalised. Almost equal proportions were in NYHA classes II and III. Echocardiography showed marked impairment of left ventricular systolic function. The main cause of CHF was ischaemic heart disease. ACE inhibitors/

\section{TABLE 1 Patient characteristics}

\begin{tabular}{lc} 
Patients $\mathbf{n}$ & 203 \\
Males & $152(75)$ \\
Hospitalised & $166(82)$ \\
Age yrs & $65.3 \pm 1.1$ \\
Body mass index $\mathbf{~ k g} \cdot \mathbf{m}^{-2}$ & $27.6 \pm 0.6$ \\
NYHA II/III & $112(55) / 91(45)$ \\
LVEF \% & $28.0 \pm 1.0$ \\
Main cause of CHF & \\
Coronary artery disease & $115(57)$ \\
Dilated cardiomyopathy & $61(30)$ \\
Hypertension & $27(13)$ \\
Atrial fibrillation & $57(28)$ \\
PCO ${ }_{2}$ mmHg & $39.7 \pm 0.8$ \\
P-blockers & $183(90)$ \\
ACE inhibitors/AT II blockers & $185(91)$ \\
Diuretics & $164(81)$ \\
Aldosterone antagonists & $93(46)$ \\
Digitalis glycosides & $85(42)$ \\
ICD & $43(21)$ \\
CRT & $17(8)$ \\
\hline
\end{tabular}

Data are presented as $\mathrm{n}(\%)$ or mean \pm SEM, unless otherwise stated. NYHA New York Heart Association; LVEF: left ventricular ejection fraction; CHF: congestive heart failure; $\mathrm{PCO}_{2}$ : carbon dioxide tension; $\mathrm{ACE}$ : angiotensinconverting enzyme; AT: angiotensin; ICD: implantable cardioverter defibrillator; CRT: cardiac resynchronisation therapy. $1 \mathrm{mmHg}=0.133 \mathrm{kPa}$. 
angiotensin II blockers and $\beta$-blockers were taken by 91 and $90 \%$ of patients, respectively. Pulmonary function testing excluded significant ventilatory deficits in all patients studied (data not shown).

\section{Prevalence and type of SDB}

Polygraphy revealed SDB in $71 \%$ of patients $(n=145)$. The mean AHI was $34 \pm 3 \cdot \mathrm{h}^{-1}$ with mean $\mathrm{Sa}, \mathrm{O}_{2} 93.1 \pm 0.3 \%$, lowest $\mathrm{Sa}_{2} \mathrm{O}_{2}$ $75.5 \pm 0.4 \%$ and the time spent with $\mathrm{Sa}_{\mathrm{a}} \mathrm{O}_{2}<90 \% 8.7 \pm 0.7 \%$ of the time spent in bed. OSA was observed in $43 \%(n=88)$ and CSR in $28 \%(n=57)$ of patients (table 2$)$. When comparing hospitalised with ambulatory patients, a similar proportion of SDB was observed (118 of the 166 hospitalised patients and 27 of the 37 ambulatory patients had SDB, i.e. 71 versus $73 \%$, respectively; $\mathrm{p}>0.05)$. Females with CHF suffered less frequently from SDB than male CHF patients ( 31 out of the 51 females and 114 of the 152 males had SDB, i.e. 61 versus $75 \%$; $\mathrm{p}<0.05$ ).

\section{Comparison of patients with OSA, CSR and without SDB}

The characteristics of the patients with OSA, CSR and without SDB are compared in tables 3 and 4 . In general, patients with SDB tended to be male. Patients with OSA were more obese than the patients in the other two groups. In addition, they suffered from more severe daytime sleepiness (i.e. they had higher Epworth scores, table 2). Patients with CSR more often had atrial fibrillation and lower $\mathrm{PCO}_{2}$ values. There were no statistically significant differences regarding NYHA classes, LVEF and the leading causes of CHF between the three groups. Except for the use of digitalis glycosides, the spectrum of medications was similar in the patients with OSA, CSR and undisturbed nocturnal breathing.

\section{DISCUSSION}

This study represents one of the largest European surveys performed to date on the occurrence of SDB in CHF patients. Participants were enrolled irrespective of the presence of sleeprelated symptoms and a high prevalence of SDB of $71 \%$ was found. It could be speculated that the percentage of patients with SDB would have been even higher if the authors had

\section{TABLE 2 Results of polygraphy}

\begin{tabular}{|c|c|c|c|}
\hline & OSA & CSR & No SDB \\
\hline Patients $\mathrm{n}$ & $88(43)$ & $57(28)$ & $58(29)$ \\
\hline Epworth score & $8.5 \pm 0.7^{\star}$ & $6.7 \pm 0.7$ & $5.8 \pm 0.8$ \\
\hline$A H I n \cdot h^{-1}$ & $34 \pm 2$ & $35 \pm 3$ & $4 \pm 1^{\star *}$ \\
\hline OAI $n \cdot h^{-1}$ & $28 \pm 2^{* *}$ & $4 \pm 2$ & $2 \pm 1$ \\
\hline CAI $n \cdot h^{-1}$ & $2 \pm 1$ & $27 \pm 3^{\star *}$ & $1 \pm 1$ \\
\hline$H I n \cdot h^{-1}$ & $4 \pm 2$ & $4 \pm 2$ & $1 \pm 1$ \\
\hline $\mathrm{Sa}, \mathrm{O}_{2} \%$ & $93.1 \pm 0.3$ & $93.0 \pm 0.4$ & $94.1 \pm 0.4$ \\
\hline lowest $\mathrm{Sa}, \mathrm{O}_{2} \%$ & $74.4 \pm 0.4$ & $77.3 \pm 0.5$ & $88.1 \pm 0.5^{\star \star}$ \\
\hline $\mathrm{Sa}, \mathrm{O}_{2}<\mathbf{9 0 \%}$ of TIB & $10.6 \pm 0.7^{\star \star}$ & $5.8 \pm 0.7$ & $3.8 \pm 0.9$ \\
\hline
\end{tabular}

Data are presented as $n(\%)$ or mean \pm SEM. OSA: obstructive sleep apnoea; CSR: Cheyne-Stokes respiration; SDB: sleep-disordered breathing; $\mathrm{AHI}$ : apnoea/hypopnoea index; OAl: obstructive apnoea index; CAl: central apnoea index; $\mathrm{HI}$ : hypopnoea index; $\mathrm{Sa}_{2} \mathrm{O}_{2}$ : oxygen saturation; TIB: time in bed. *: $p<0.05$ and ${ }^{* *}: p<0.01$ in comparison with the other two groups

\begin{tabular}{|c|c|c|c|c|}
\hline \multirow[t]{2}{*}{ TABLE 3} & \multicolumn{4}{|c|}{$\begin{array}{l}\text { Anthropometric data, New York Heart } \\
\text { Association (NYHA) classes, left ventricular } \\
\text { ejection fraction (LVEF) and causes of cardiac } \\
\text { failure in the patients with obstructive sleep } \\
\text { apnoea (OSA), Cheyne-Stokes respiration (CSR) } \\
\text { and without sleep-disordered breathing (SDB) }\end{array}$} \\
\hline & & OSA & CSR & No SDB \\
\hline \multicolumn{2}{|l|}{ Patients n } & 88 & 57 & 58 \\
\hline \multicolumn{2}{|l|}{ Males } & 67 (76) & $47(82)$ & $38(66)^{*}$ \\
\hline \multicolumn{2}{|l|}{ Hospitalised } & $69(78)$ & $49(86)$ & $48(83)$ \\
\hline \multicolumn{2}{|l|}{ Age yrs } & $64.7 \pm 1.1$ & $67.2 \pm 1.2$ & $64.2 \pm 1.2$ \\
\hline \multicolumn{2}{|c|}{ Body mass index $\mathrm{kg} \cdot \mathrm{m}^{-2}$} & $29.0 \pm 0.5^{\star}$ & $26.7 \pm 0.6$ & $26.5 \pm 0.6$ \\
\hline \multicolumn{2}{|l|}{ NYHA II } & $50(57)$ & $32(56)$ & $30(52)$ \\
\hline \multicolumn{2}{|l|}{ NYHA III } & $38(43)$ & $25(44)$ & $28(48)$ \\
\hline \multicolumn{2}{|l|}{ LVEF \% } & $28.6 \pm 0.9$ & $26.8 \pm 1.0$ & $28.4 \pm 1.0$ \\
\hline \multicolumn{5}{|c|}{ Main cause of $\mathrm{CHF}$} \\
\hline \multicolumn{2}{|c|}{ Coronary artery disease } & $51(58)$ & $33(58)$ & $31(53)$ \\
\hline \multicolumn{2}{|c|}{ Dilated cardiomyopathy } & $25(28)$ & $17(30)$ & $19(33)$ \\
\hline \multicolumn{2}{|c|}{ Hypertension } & $12(14)$ & 7 (12) & $8(14)$ \\
\hline \multicolumn{2}{|c|}{ Atrial fibrillation } & $19(22)$ & $25(44)^{*}$ & $13(22)$ \\
\hline \multicolumn{2}{|l|}{$\mathrm{PCO}_{2} \mathrm{mmHg}$} & $40.6 \pm 0.8$ & $36.8 \pm 0.8^{* *}$ & $41.3 \pm 0.9$ \\
\hline
\end{tabular}

investigated only CHF patients with snoring, witnessed apnoeas and excessive daytime sleepiness. Such an approach would probably have further increased the proportion of patients with OSA, as these are usually more symptomatic than those with CSR. This was also the case in the current series, with the OSA patients displaying higher Epworth scores than the CSR patients.

As in other studies $[5,6]$, patients with OSA were more obese than those with CSR or without SDB, whereas CSR was more often observed in patients who were in atrial fibrillation and/ or were hypocapnic. The present authors believe that these characteristics can be used in clinical practice to identify those $\mathrm{CHF}$ patients who are at a higher risk for SDB.

Recognising that a patient with CHF suffers from SDB may have important clinical implications. OSA can contribute to the worsening of CHF through various mechanisms. The intrathoracic pressure swings associated with OSA may directly depress cardiac contractility. Furthermore, OSA may lead to $\mathrm{CHF}$ by promoting the development of arterial hypertension and ischaemic heart disease [7, 8]. Likewise, some studies suggest that CSR has a negative impact on the prognosis of CHF $[9,10]$. This effect is presumably mediated by an enhancement of the neurohumoral changes characteristic of $\mathrm{CHF}$, such as sympathetic and natriuretic peptide activation $[11,12]$. Furthermore, CSR may trigger malignant arrhythmias leading to sudden cardiac death [13].

The prevalence of SDB in the current CHF patients was similar or even higher than that reported in the literature. However, it is difficult to compare the results of the present study to those obtained in earlier studies for several reasons. First, most of the 


\begin{tabular}{|c|c|c|c|c|}
\hline \multirow[t]{2}{*}{ TABLE 4} & \multicolumn{4}{|c|}{$\begin{array}{l}\text { Therapy of heart failure in the patients with } \\
\text { obstructive sleep apnoea (OSA), Cheyne-Stokes } \\
\text { respiration (CSR) and without sleep-disordered } \\
\text { breathing (SDB) }\end{array}$} \\
\hline & & OSA & CSR & No SDB \\
\hline \multicolumn{2}{|l|}{ Patients $\mathrm{n}$} & 88 & 57 & 58 \\
\hline \multicolumn{2}{|l|}{$\beta$-blockers } & $81(92)$ & $52(91)$ & $50(86)$ \\
\hline \multicolumn{2}{|c|}{$\begin{array}{l}\text { ACE inhibitors/AT II } \\
\text { blockers }\end{array}$} & $83(94)$ & $52(91)$ & $50(86)$ \\
\hline \multicolumn{2}{|l|}{ Diuretics } & $71(81)$ & $46(81)$ & $47(81)$ \\
\hline \multicolumn{2}{|c|}{ Aldosterone antagonists } & $40(45)$ & $25(44)$ & $28(48)$ \\
\hline \multicolumn{2}{|c|}{ Digitalis glycosides } & $34(39)$ & $30(53)^{\star}$ & $21(36)$ \\
\hline \multicolumn{2}{|l|}{ ICD } & $18(20)$ & $14(25)$ & $11(19)$ \\
\hline \multicolumn{2}{|l|}{ CRT } & $8(9)$ & $5(9)$ & $4(7)$ \\
\hline
\end{tabular}

Data are presented as $n(\%)$, unless otherwise stated. ACE: angiotensinconverting enzyme; AT: angiotensin; ICD: implantable cardioverter defibrillator; CRT: cardiac resynchronisation therapy. ${ }^{*}: p<0.05$ in comparison with the other two groups.

earlier studies were performed at single well-known referral centres, whereas the current patients were enrolled at different clinical institutions of pulmonary and general internal medicine located throughout Germany. Secondly, studies employed different scoring criteria for SDB. For example, the AHI cut-off value in the present study was $10 \cdot \mathrm{h}^{-1}$, whereas JAVAHERI et al. [4] used a cut-off of $15 \cdot h^{-1}$. It has also to be considered that in the present study the AHI was expressed as the number of apnoeas and hypopnoeas per hour of time in bed (and not per hour of total sleep time as in most preceding studies). Thirdly, the sleep recordings from the different studies were scored by different investigators, thus introducing inter-rater variability. Fourthly, there were differences in monitoring techniques of sleep and breathing between studies. In contrast to the other studies, which mainly employed in-hospital polysomnography, the present authors used a polygraphic device. Due to the lack of electroencephalographic channels, some hypopnoeas associated with arousals rather than with oxygen desaturations may have been missed. However, pressure cannulae were used for the detection of apnoeas/hypopnoeas, which are more sensitive than the thermistors used in the earlier studies [14].

In contrast to most preceding studies on the epidemiology of sleep apnoea in CHF, the predominant type of SDB in the current study was OSA and not CSR. Sometimes it is difficult to classify cases of SDB as OSA or CSR. For instance, differentiating between obstructive and central hypopnoeas can be very challenging, especially when only the signals of inductive plethysmography are relied upon.

In the current study, however, scoring of SDB was further refined by using additional information from the snoring and airflow channels (i.e. obstructive events had to display snoring and/or flattening of the inspiratory flow contour). A further point to consider is that some CHF patients may exhibit features of both OSA and CSR (mixed sleep apnoea); however, all patients of the present study had either predominant OSA or CSR. Therefore, the authors suggest that the observed shift in the spectrum of SDB cannot be explained by relevant misclassification of SDB but is primarily related to differences in patient characteristics between studies. In this context, it is known that more severely reduced LVEF and higher NYHA classes are associated with an increased risk to develop CSR $[15,16]$. In the current patients, however, left ventricular function was better preserved and all of them were stable in NYHA classes II and III. This might have contributed to a higher proportion of OSA cases in the present study. In addition, when compared with earlier studies, the current patients were characterised by a more widespread use of $\beta$ blockers. The present authors speculate that this optimisation in pharmacotherapy of CHF led to the disappearance of CSR in a subset of patients. $\beta$-blockers might suppress CSR not only by decreasing circulation times and pulmonary venous congestion but also by altering chemoreflex regulation of ventilatory control [17]. It is worth noting that this assumption is supported by two recent studies showing that CHF patients taking $\beta$-blockers have a lower prevalence and severity of CSR than those who do not $[18,19]$.

Similar to pharmacotherapy, mechanical devices used for the treatment of advanced $\mathrm{CHF}$, such as cardiac re-synchronisation therapy, have been reported to improve or even abolish CSR [20]. In the present study, only a minority of patients received this form of therapy and therefore, this issue cannot be addressed. However, it should be kept in mind that an optimisation of CHF treatment in a more general sense might impact on the occurrence of SDB in these patients.

It should be acknowledged that the current study has some possible limitations. As already stated, polygraphy was performed, which might be inferior to polysomnography. However, a study investigating the ability of polygraphy to detect SDB in patients with CHF showed that there was no significant difference when compared with polysomnography [21]. Furthermore, blinded visual analysis of all polygraphic data was performed at a single centre thus minimising possible bias induced by inter-observer variability. Secondly, as mainly hospitalised CHF patients of male sex were included, the current findings might not be extrapolated to outpatients and females with CHF. Although a similar proportion of SDB was observed in ambulatory versus hospitalised patients, it has to be taken into account that ambulatory CHF patients frequently do not receive medical therapy according to established guidelines [22]. One may suspect that this may lead to a higher percentage of CSR in these patients. As far as the effects of sex on the occurrence of SDB in CHF are concerned, it has been reported that male sex is associated with a higher likelihood to develop both OSA and CSR [5]. The present authors also found a higher percentage of males in those patients suffering from SDB. Thus, if more females had been included, the proportion of patients with sleep apnoea would probably have been lower.

\section{Summary}

The current authors have shown that the prevalence of sleepdisordered breathing is high in patients with stable severe congestive heart failure from a European population. Due to the potential adverse effects of sleep-disordered breathing on the clinical course of congestive heart failure, the authors suggest that a sleep study should be performed in every 
patient with congestive heart failure and a left ventricular ejection fraction $<40 \%$. This diagnostic approach should probably be adopted for all of these patients irrespective of the presence of sleep-related symptoms.

\section{ACKNOWLEDGEMENTS}

The present study contains parts of the MD theses of A. Jäkel (Dept of Cardiology/Pulmonary Medicine, University Hospital Bonn, Bonn), F. Kleinsorge (University of Giessen Lung Centre, Giessen), K. Preuß (Pius Hospital, Oldenburg), S. Rheinländer (Dept of Pulmonary Medicine, Ruhr University Hospital Bochum, Bochum) and H. Semper (Dept of Cardiology/Pulmonary Medicine, University of Gottingen, Gottingen, all Germany). The authors would like to thank M. Glos, Sleep Laboratory of the Charité University Hospital, (Berlin, Germany) for his excellent technical support.

\section{REFERENCES}

1 Study group on Heart Failure Awareness and Perecption in Europe. www.heartfailure-europe.com. Date last accessed: January 2007.

2 Levy D, Kenchaiah S, Larson MG, et al. Long-term trends in the incidence of and survival with heart failure. $N$ Engl J Med 2002; 347: 1397-1402.

3 Javaheri S, Parker TJ, Wexler L, et al. Occult sleepdisordered breathing in stable congestive heart failure. Ann Intern Med 1995; 122: 487-492.

4 Javaheri S, Parker TJ, Liming JD, et al. Sleep apnea in 81 ambulatory male patients with stable heart failure. Types and their prevalences, consequences and presentations. Circulation 1998; 97: 2154-2159.

5 Sin DD, Fitzgerald F, Parker JD, Newton G, Floras JS, Bradley TD. Risk factors for central and obstructive sleep apnea in 450 men and women with congestive heart failure. Am J Respir Crit Care Med 1999; 160: 1101-1106.

6 Javaheri S, Corbett WS. Association of low $\mathrm{paCO}_{2}$ with central sleep apnea and ventricular arrhythmias in ambulatory patients with stable heart failure. Ann Intern Med 1998; 128: 204-207.

7 Peppard PE, Young T, Palta M, Skatrud J. Prospective study of the association between sleep-disordered breathing and hypertension. N Engl J Med 2000; 342: 1378-1384.

8 Peker Y, Carlson J, Hedner J. Increased incidence of coronary artery disease in sleep apnoea: a long-term follow-up. Eur Respir J 2006; 28: 596-602.

9 Hanly PJ, Zuberi-Khokhar NS. Increased mortality associated with Cheyne-Stokes respiration in patients with congestive heart failure. Am J Respir Crit Care Med 1996; 153: 272-276.

10 Lanfranchi PA, Braghiroli A, Bosimini E, et al. Prognostic value of nocturnal Cheyne-Stokes respiration in chronic heart failure. Circulation 1999; 99: 1435-1440.

11 Carmona-Bernal C, Quintana-Gallego E, Villa-Gil M, Sanchez-Armengol A, Martinez-Martinez A, Capote F. Brain natriuretic peptide in patients with congestive heart failure and central sleep apnea. Chest 2005; 127: 1667-1673.

12 van de Borne P, Oren R, Abouassaly C, Anderson E, Somers VK. Effect of Cheyne-Stokes respiration on muscle sympathetic nerve activity in severe congestive heart failure secondary to ischemic or idiopathic dilated cardiomyopathy. Am J Cardiol 1998; 81: 432-436.

13 Leung RS, Diep TM, Bowman ME, Lorenzi-Filho G, Bradley TD. Provocation of ventricular ectopy by Cheyne-Stokes respiration in patients with heart failure. Sleep 2004; 27: 1337-1343.

14 Norman RG, Ahmed MM, Walsleben JA, Rapoport DM. Detection of respiratory events during NPSG: nasal cannula/pressure sensor versus thermistor. Sleep 1997; 20: 1175-1184.

15 Tremel F, Pepin JL, Veale D, et al. High prevalence and persistence of sleep apnoea in patients referred for acute left ventricular failure and medically treated over 2 months. Eur Heart J 1999; 20: 1201-1209.

16 Mared L, Cline C, Erhardt L, Berg S, Midgren B. CheyneStokes respiration in patients hospitalised for heart failure. Respir Res 2004; 5: 14.

17 Campbell SC, Lauver GL, Cobb RB Jr. Central ventilatory depression by oral propranolol. Clin Pharmacol Ther 1981; 30: 758-764.

18 Köhnlein T, Welte T. Does beta-blocker treatment influence central sleep apnoea? Respir Med 2007; 101: 850-853.

19 Tamura A, Kawano Y, Naono S, Kotoku M, Kadota J. Relationship between beta-blocker treatment and the severity of central sleep apnea in chronic heart failure. Chest 2007; 131: 130-135.

20 Gabor JY, Newman DA, Barnard-Roberts V, et al. Improvement in Cheyne-Stokes respiration following cardiac resynchronisation therapy. Eur Respir J 2005; 26: 95-100.

21 Quintana-Gallego E, Villa-Gil M, Carmona-Bernal C, et al. Home respiratory polygraphy for diagnosis of sleepdisordered breathing in heart failure. Eur Respir J 2004; 24: 443-448.

22 Drechsler K, Dietz R, Klein H, et al. Euro heart failure survey. Medical treatment not in line with current guidelines. Z Kardiol 2005; 94: 510-515. 